biological standards. Two are in Britain at the National Institute of Medical Research and at the Central Veterinary Laboratory, Weybridge. The work of these institutes is characteristic of the fundamental support which W.H.O. provides for modern medicine. The preparations available cover a wide range, including blood typing sera, enzymes and hormone preparations, plasma protein fractions such as coagulation factors, antibiotics, immune sera, vaccines, and many others. The principle is to provide preserved materials of measured stability whose activity is ascertained in recognized centres by biological or microbiological assay. It is not often possible to describe the activity of such preparations in absolute terms, and the empirical approach of agreed international units of activity has proved its worth in practice.

More recently the need for standard reference preparations has extended through the rapid expansion of laboratory medicine and of clinical chemistry in particular. A number of independent bodies, such as the International Federation of Clinical Chemists, have convened committees on standards. Progress has been slow, and the interrelation of assay methods and standardization has emerged as a field for investigation which has so far received little attention. Techniques for the validation of assay methods are still comparatively crude. A further need for standardization arises from international survey work on such matters as nutritional status in different communities, and here substances such as iron, vitamin $\mathbf{B}_{12}$, and folate are important. Two main approaches have been used. The first is essentially empirical and consists in the distribution of preserved specimens, usually of sera, to a number of laboratories, whose results are statistically analysed. The common experience of a group of laboratories is used as a measure of the precision of each. The second approach is the production of standard reference preparations in which the active component is described in absolute units.

The International Committee for Standardization in Haematology (I.C.S.H.) performed a notable service to medicine when it succeeded in obtaining widespread agreement for the specification of a standard haemoglobin preparation now in worldwide use. ${ }^{1}$ We may now with some confidence compare results of haemoglobinometry from reputable laboratories no matter where they may be. It is a measure of the problems of standardization that this agreement took many years to achieve in spite of the fact that the concentration of haemoglobin in blood is high and measured in grammes per $100 \mathrm{ml}$, that its molecular weight and structure are known with some accuracy, and the absorption characteristics of its derived pigments are well characterized. No other single substance in blood occurs in such concentration. The problems are multiplied when dealing with concentrations measured in milligrams per $100 \mathrm{ml}$ and even more so with the trace substances measured in micrograms.

However, encouraged by this success the International Committee enlarged the range of its activities and convened a number of panels for specific problems. Recently its Expert Panel on Iron, set up in 1966, has made a first report recommending a provisional specification for a standard serum iron preparation. ${ }^{2}$ The recommendations are based on investigations undertaken by the panel which were described in a symposium at the Thirteenth Congress of the International Society of Haematology in Munich in $1970 .^{3}$

It might be expected that substances which can be prepared in highly purified form would lend themselves to simple standards of pure substance. It is indeed not difficult to prepare highly accurate standard aqueous solutions of many substances, including iron, commonly assayed in clinical chemistry. But problems arise from differences between organic media and aqueous solutions, in some cases from the instability of the pure substance, from binding or partial binding with proteins, from changes in fluid volume which occur on protein precipitation or dialysis, from the reconstitution of freeze-dried material to original volume, and from the presence of interfering substances-e.g., haemoglobin in iron assay. Attempts to define standards in absolute terms must take such problems of technique into account.

An interesting feature of the present provisional recommendations for iron assay is that the standard preparation should consist of two specimens with a difference in concentration of the variable-in this case the concentration of iron-of an accurate pre-determinable amount. When biochemical assays involve substances which can be prepared with known chemical purity, this approach to standardization offers the possibility of assay standards of a high order of accuracy. It may be applicable to many clinical biochemical assays and deserves careful study.

It is apparent from the report of the Expert Panel on Iron that the I.C.S.H., as well as seeking international agreement in its field of interest, is successfully promoting joint international research to achieve its objective. But clearly the various bodies now exploring standardization procedures should be brought together to co-ordinate their efforts, and the W.H.O. would seem to be the natural agency to undertake this.

1 British fournal of Haematology, 1967, Supplement 13, p. 71.

2 British fournal of Haematoi
3 To be published shortly.

\section{Science on Show}

In one of those reflective moments that come to young and old alike the question is sometimes posed: What is science? And the answer often boils down in the end to some version of: It is what scientists do. Though not very helpful to the logician that lurks in all of us, this conclusion does have the merit of emphasizing the personal responsibility of men for their conduct. Science comprises certain activities of people making decisions in play or earnest. Something of the imagination and ingenious thought that go into scientific research appears on stage periodically at the Royal Society's conversaziones, of which one was held last week to entertain the Fellows and their guests.

Among the exhibits displayed in the society's rooms at Carlton House Terrace was one by Dr. R. F. Hellon, of the National Institute for Medical Research, on the thermostat that keeps the body's temperature so remarkably constant. It consists of cells in the hypothalamus that are specially sensitive to their own temperature and also responsive to nervous impulses from receptors in the skin. Receiving information from inside and outside the body, it then controls the reactions of shivering, sweating, and so on to maintain a constant temperature. Drs. P. Pearson and $M$. Bobrow, of the M.R.C.'s Population Genetics Unit at Oxford, showed how fluorescent staining of human chromosomes with quinacrine dihydrochloride could distinguish each one individually. The technique was pioneered at the Karolinska Institute in Stockholm. Bands of fluorescence make a characteristic pattern on each chromosome, and for some unknown reason the $\mathrm{Y}$ chromosome always shows much brighter 
fluorescence than the rest. Dr. P. M. A. Rabbit and $\mathrm{Mr}$. S. M. Vyas, of the Institute of Experimental Psychology at Oxford, are investigating the speed with which a person responds to a visual stimulus in relation to whether a previous stimulus was the same or different. They showed that, as might be expected, the second response was faster than the first if the two stimuli were similar in characters that had to be watched for. But they also showed that other characters not watched for quickened the response even more. Thus the first response seems to depend on a perception of the whole displayed object rather than individual features of it.

Since much the greater part of the earth's surface is covered with water, it is only right that we should be deeply concerned about its denizens, and two exhibits were on this theme. The Government's Fisheries Radiobiological Laboratory at Lowestoft in Suffolk controls the main discharges of radioactive waste into lakes, rivers, and seas, giving advice as well as monitoring the disposal of this most dangerous of man's effluvia. Among its investigations is one into the chronic effects of gamma-radiation on fish. Government laboratories at Burnham on Crouch in Essex and at Pitlochry in Perthshire also had a joint demonstration of their work on the monitoring of pesticides in fish.

These two exhibits are symptomatic of a slight change in emphasis on the direction of scientific research. Though it may be carried out primarily to satisfy man's curiosity, the justification is commonly advanced that research is for his benefit. Now the question is being asked whether it is also for the benefit of other living organisms for the destruction of species and their habitats in the last hundred years is nothing less than alarming.

\section{Riots and Health}

In all conflicts the combatants make the headlines, their destruction provides the pictures, the underlying issues are the subject of public discussion. And always, peaceful people are drawn into the strife, their suffering is bitter, and most of the time it passes unnoticed. Now two psychiatrists have attempted to measure the effects of this suffering by recording the incidence of psychiatric disorder after the rioting in Belfast in August and September 1969.

R. M. Fraser ${ }^{1}$ has made a controlled retrospective survey of hospital records, which showed no increase in the numbers of patients referred to psychiatrists or admitted to psychiatric wards from areas directly involved in rioting, though there was a highly significant increase in the number of prescriptions given for tranquillizers. From areas where the disturbance was "comparatively slight" there were substantial increases in psychiatric referrals and admissions, but no great change in the prescriptions for tranquillizers.

H. A. Lyons ${ }^{2}$, also retrospectively, studied the reaction pattern of 217 patients seen by general practitioners and 40 referred to psychiatrists, all of whose psychiatric symptoms were judged to be related to the riots. The whole range of psychiatric symptomatology was observed, but "acute situational anxiety" or "anxiety state" was the diagnosis for over two-thirds. Just over half of these gave no history of previous psychiatric disorder, while only a quarter of those with other diagnoses gave no previous psychiatric history. Psychotic reactions were rare.

The two papers are broadly in agreement. Fraser's results suggest that the proximity to and the threat of violence may produce mental disorder (classified as either "neurotic" or "psychotic"), but that the actual experience of rioting and burning led only to increases in prescriptions for tranquillizers. They were presumably given to patients with acute anxiety symptoms, such as Lyons's patients, all of whom were drawn from the riot areas.

These findings invite comparison with the effects of the bombing of Britain on the mental health of civilians in the second world war. The two large surveys of $\mathrm{A}$. Lewis ${ }^{3}$ and C. P. Blacker ${ }^{4}$ show that the rise was minimal, and these with other published accounts suggest that acute anxiety reactions were rare. But in war the issues are clear-cut, the enemy can easily be identified, and there is general dedication to the war effort. In civil conflict the objectives are far from clear, the enemy may be ill-defined, and no refuge is really secure. If there is any solidarity it is purely local, so that morale is likely to be rather low, and political wrangling is apt to weaken it anyway. Persistent fear, uncertainty, and frustration in face of a threat which cannot be precisely identified provides a setting for stress symptoms of any kind. After months of strife in Belfast there may now be a large number of people who are showing measurable signs of distress. But what are the appropriate measures?

Fraser and Lyons showed that there was no dramatic increase in mental ill health, and that is in line with the wartime reports. Studies of the incidence of physical conditions tell another story. J. N. Morris and R. M. Titmuss ${ }^{5}$ found a substantial rise in deaths from peptic ulcer in London after the air raids of 1940 , while they rose only slightly in the rest of England and Wales. The United States Strategic Bombing Survey of Europe $^{6}$ reported that an "analysis of data from governmental insurance groups demonstrates an unmistakable increase in the incidence of ulcer patients during the war years and especially during periods in which the particular areas were subjected to bombing. Furthermore, the areas which received little or no bombing showed little or no increase in the incidence of peptic ulcer." It also found "a distinct rise in the incidence of coronary heart disease." H. G. Wolff found a much higher than expected number of deaths from heart disease, cancer, accidents, suicide, and pulmonary tuberculosis among American servicemen who had been prisoners-of-war of the Japanese. After the Bristol floods of $1968 \mathrm{G}$. Bennet ${ }^{8}$ reported among the victims a substantial rise in the number of attendances at general practitioners' surgeries, referrals to hospital, and hospital admissions. And they had diagnoses of all kinds, not just those which might have been considered to be a direct consequence of flooding. Further, the mortality rate of those flooded increased by $50 \%$ over the subsequent 12 months.

People respond to civil disaster much as they respond to a bereavement, and an increased morbidity and mortality among the bereaved has often been reported. It may be therefore that these reports from Belfast are understating the real situation, that the people's suffering will turn out to be even greater than had been supposed, and that it will not stop when the last bullet has been fired.

1 Fraser, R. M., British Fournal of Psychiatry, 1971, 118, 257

2 Lyons, H. A., British Fournal of Psychiatry, 1971, 118, 265.

3 Lewis, A., Lancet, 1942, 2, 175.

Blacker C. P., Neurosis and the Mental Health Services, London, Oxford, 1946

5 Morris, J. N., and Titmuss, R. M., Lancet, 1944, 2, 841.

United States Strategic Bombing Survey, The Effect of Bombing on Health and Medical Care in Germany. Washington D.C., U.S. Go rernment Printing Office, 1945, p. 99.

Wolf, H. G., in Stress and Psychiatric Disorder, ed. J. M. Tanner, p. 29. Oxford, Blackwell, 1960. 